\title{
Patterns of Dermatological manifestation in patients attending Pediatric outpatient department
}

\author{
Arjun Bhattarai ${ }^{1 *}$ (D), Bandana Shrestha ${ }^{1}$, Ravi Raj Timasina ${ }^{2}$, Nawaraj KC ${ }^{3}$, Shankar Poudel', \\ and Saraswati Neupane ${ }^{4}$
}

'Department of Pediatrics, ${ }^{2}$ Department of Psychiatry, ${ }^{4}$ Department of Dermatology, Gandaki Medical College, Pokhara, ${ }^{3}$ Department of Pediatrics, Karnali Province Hospital, Surkhet

\begin{abstract}
Background: Dermatological manifestations in children contribute to significant morbidity and psychological distress. Children with dermatological problems constitute a major bulk of the patients presenting to the Outpatient department. The study was conducted with an objective to find out the pattern of skin disease among the various pediatric age group. Method: We analyzed epidemiological data of 612 patients, aged 1 months to 15 years, who were referred to the Dermatology outpatient from the Pediatric outpatient between 2nd Baisakh 2075 to 31 Chaitra 2076. Demographic data and the frequency of the various diagnoses in various age groups were studied. Result: The most common category of diagnosis was infection in $35.78 \%$, followed by allergic reaction in $33.50 \%$ and infestations in $14.22 \%$, other dermatosis in $13.07 \%$, while multiple diagnosis was found in $3.43 \%$. Among all diagnostic groups, Scabies was the most common (14.22\%) followed by Urticaria (11.92\%). Conclusion: Comparison of the common dermatosis with the age group showed a strongly significant effect on occurrence of common dermatosis. Their incidence can be brought down by improving nutrition and personal hygiene of children. Health and wellness of school going children reflects the health status of a community. Our study provides a preliminary baseline data for future epidemiological and clinical research.
\end{abstract}

Keywords: Dermatology, infections, infestations, pediatrics

\section{Correspondence to:}

Dr Arjun Bhattarai

Lecturer, Department of Pediatrics, Gandaki Medical College, Pokhara

E-mail: arjunbhattarai714@gmail.com

Submitted: September 1, 2020

Accepted: November 11, 2020

To cite: Bhattarai A, Shrestha B, Timasina RR, KC N, Poudel S, Neupane S. Patterns of Dermatological manifestation in patients attending Pediatric outpatient department.

JGMC Nepal. 2020;13(2):160-3.

DOI: 10.3126/jgmcn.v13i2.30960

\section{INTRODUCTION}

Of the total outpatients visit in pediatric facility more than $30 \%$ is contributed by dermatological manifestations. ${ }^{1,2}$ Ethnic, socioeconomic, and environmental factors influence their incidence. Chronic skin diseases such as psoriasis, xeroderma pigmentosum, neurofibromatosis are a source of social stigmatization with widespread belief that these problems are contagious and related to impurities in the blood. ${ }^{3}$ According to the Ministry of Health and population in Nepal, skin manifestations are the cause of morbidity with about 2,700,000 and 2,680,000 outpatient visits of skin disease in 2009 and $2010 .{ }^{4}$ The prevalence of skin disease in children in Western Nepal was found to be at $13.46 \% .{ }^{5}$ The pattern of skin diseases is known to differ in different countries of the world and in different region in the country. ${ }^{6}$ The aim of this study was to estimate the incidence rates of pediatric skin diseases in our region that can subsequently serve as reference material for future comparative studies. 


\section{METHODS}

This was a retrospective study conducted in outpatient units of department of pediatrics at Gandaki Medical College Teaching Hospital, a tertiary care referral hospital situated in Pokhara Metropolitan of Gandaki Province of Nepal. The data from registry of the departments, was reviewed and data of the year 2075 Baisakh to Chaitra 2075 was collected after due ethical clearance from the Gandaki Medical College Institutional Review Committee. The collected data included all the patients visiting the pediatric OPD from the age of one month to 15 years who presented with dermatological disorder and further referred to the department of dermatology for diagnosis and management. The diagnosis was recorded in pediatric OPD. The patients below the age of 1 months were excluded due to the possibility of various birth marks and rashes occurring due to the birthing process and above 15 years of age were not seen in pediatric OPD.

The patients were grouped on basis of gender and into four age group categories as: Infants 1 to 12 months, toddler $>1$ to 3 years, preschool $>3$ to 6 years, school going $>6$ to 12 years and rest as others $>12$ to 15 years of age. The diagnosis made by the consultant Dermatologist in the department of dermatology was taken into account and the various diagnosis was grouped as infections, Infestations and others dermatosis. The data was analyzed for the demographic variables, and the various statistical tools applied by using SPSS version 25 for Mac (IBM Corp.).

\section{RESULTS}

During the period of one year, 612 children were examined for the first time in the department of pediatrics and hence referred to the department of dermatology. Six hundred and twelve patients with various diagnosis, consisted of males 321 (52.5\%) and females 291 (47.5\%).

Based on the age group, 73 were infants (11.93\%), 134 were toddlers (21.90\%), 54 were preschoolers (8.82\%), 298 (48.69\%) were school going and 53 (8.66\%) were of the others age group category. Based on the geographical distribution, 404 were from urban area of inhabitance (66\%), and 208 were from rural area of inhabitance (34\%). Based on different ethnic groups, 154 were Brahmin (25.2\%), 78 were Chettri (12.7\%), 154 were Dalit (25.2\%), 162 were Janajati (26.5), 4 were Muslim (0.7\%), 44 were Newar (7.2\%) and 16 were others (2.6\%) including Marwari, Bengali, Jain.

Table 1 shows the type of dermatitis with the most common being infection (35.78\%) followed by allergic reaction (33.5\%), infestation (87), other dermatosis $(13.07 \%)$ and multiple diagnosis $(3.43 \%)$. The most common type of infection was Impetigo (Table 2). Table 3 shows the most common type of allergic reaction was urticaria (11.93\%). The most common type of dermatitis among other dermatosis was acne $(6.7 \%)$ (Table 4$)$.

Figure 1 shows the distribution of various dermatosis based on age group. It can be seen that incidence of allergic reactions was most common in infants, followed by infestations and infections. While in the toddlers, allergic reaction was commonest followed by infection, infestation and other dermatosis. In the preschooler age, same pattern was observed except with increase in the incidence of infectious diseases. Among school going and others group of children, infectious disease was the most common followed by allergic reaction, other dermatosis and infestations.

Table 1: Spectrum of dermatosis

\begin{tabular}{ll}
\hline Type of diagnosis & Frequency (\%) \\
\hline Infection & $219(35.78)$ \\
Allergic Reaction & $205(33.50)$ \\
Infestation & $87(14.22)$ \\
Other Dermatosis & $80(13.07)$ \\
Multiple & $21(3.43)$ \\
Total & $612(100)$ \\
\hline
\end{tabular}

Table 2: Patient distribution based on different dermatosis (Infections)

\begin{tabular}{ll}
\hline Infections & Frequency $\mathbf{( \% )}$ \\
Impetigo & $21(3.43)$ \\
Abscess & $3(0.49)$ \\
Balanitis & $2(0.33)$ \\
Cellulitis & $2(0.33)$ \\
Candidal Intertrigo & $3(0.49)$ \\
Chicken pox & $41(6.70)$ \\
Furuncle & $3(0.49)$ \\
Herpes Zoster & $7(1.14)$ \\
HFMD & $19(3.10)$ \\
Molluscum contagiosa & $17(2.78)$ \\
Omphalitis & $1(0.16)$ \\
Onchomycosis & $4(0.65)$ \\
P.alba & $11(1.80)$ \\
P. versicular & $9(1.47)$ \\
P. rosea & $4(0.65)$ \\
Pyoderma & $2(0.33)$ \\
T. cruris & $13(2.12)$ \\
T. manum & $5(0.82)$ \\
T. Pedis & $15(2.45)$ \\
T. Capitis & $8(1.31)$ \\
T. Corporis & $15(2.45)$ \\
Veruca plana & $4(0.65)$ \\
Veruca vulgaris & $3(0.49)$ \\
Vulvo vaginal candidiasis & $3(0.49)$ \\
Viral exanthoma & $2(0.33)$ \\
\hline & $2(0.33)$ \\
Total & $219(35.78)$ \\
\hline
\end{tabular}


Table 3: Patient distribution based on different dermatosis (Allergic reaction )

\begin{tabular}{ll}
\hline Allergic Reaction & Frequency $(\%)$ \\
Angioedema & $6(0.98)$ \\
Contact Dermatitis & $41(6.70)$ \\
Eczema & $31(5.07)$ \\
Palmo plantar Hypersensitivity & $3(0.49)$ \\
Pompholyx & $1(0.16)$ \\
Pruritis & $5(0.82)$ \\
Seborrheic Dermatitis & $45(7.35)$ \\
Urticaria & $73(11.93)$ \\
& $205(33.50)$ \\
\hline
\end{tabular}

Table 4: Patient distribution based of different dermatosis (Other)

\begin{tabular}{ll}
\hline Other Dermatoses & Frequency (\%) \\
Acne & $41(6.70)$ \\
Alopecia areta & $3(0.49)$ \\
Chilblains & $3(0.49)$ \\
Eepidermal Naevus & $2(0.33)$ \\
Icthyosis & $3(0.49)$ \\
Milaria & $5(0.82)$ \\
Porphyria & $1(0.16)$ \\
Post inflammatory hyperpigmentation & $2(0.33)$ \\
Post inflammatory hypopigmentation & $3(0.49)$ \\
Psoriasis & $3(0.49)$ \\
Segmental nevus & $3(0.49)$ \\
SLE & $1(0.16)$ \\
Tuberous sclerosis & $2(0.33)$ \\
Vitiligo & $8(1.31)$ \\
$\quad$ Total & 80 \\
\hline
\end{tabular}

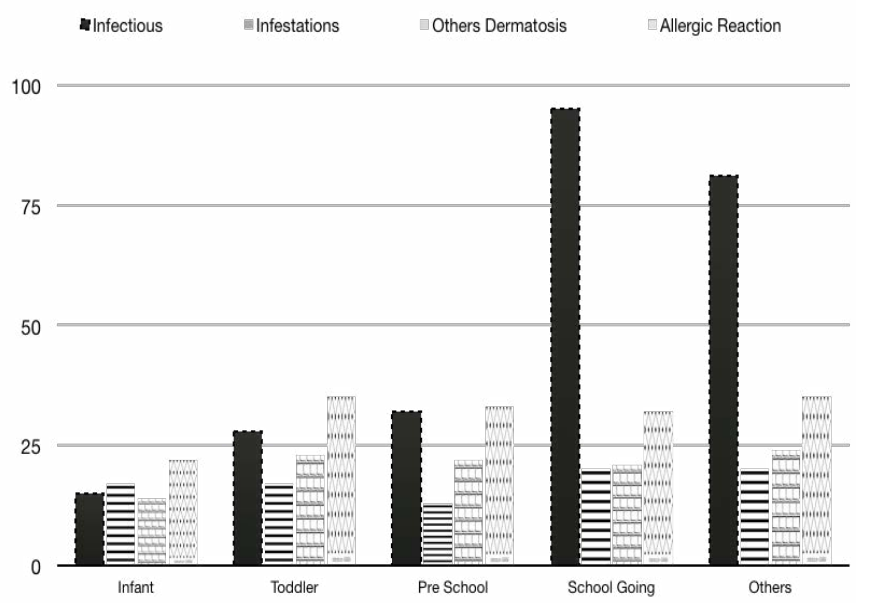

Figure 1: Distribution of various dermatosis based on age group

\section{DISCUSSION}

There is a huge gap of epidemiological data in pediatric dermatoses in our region. This retrospective study was done to find out the prevalence of different dermatological manifestations in the pediatric age group in a tertiary care hospital in Gandaki state of Nepal. We also tried to categorize the various diagnosis based on the age group of the pediatric population also.

Dermatological manifestations have been found to vary from one geographical location to another, one state to another and also among various socioeconomic classes of the individuals also. With the paucity of data in pediatric dermatosis, we have tried to compare our data with various studies done in and around Indian subcontinent as we have multiple similarities socially and culturally. The male : female ratio of $1.1: 1$ was found in our study. This corresponds with the findings of a similar study done in Western Nepal. ${ }^{7}$ Among the infections the most common was Chicken pox ( 6.70\%) followed by Impetigo $\mathrm{n} 21$ (3.43\%) which also corresponds to a similar study.

In the allergic reaction group of diagnosis the most common was dermatitis n86 (14.05\%) followed by urticaria n73 ( $11.93 \%)$ and eczema n31 (5.07\%) which was similar to results as found in other studies of the region..$^{8-12}$ The most common dermatological manifestation observed was comparable to western studies ${ }^{13}$ rather than to south Asian studies ${ }^{14}$, the derivation of majority of our patients were from the urban areas, which could have lead to the similar presentation as the study performed in Kathmandu Nepal. ${ }^{8}$ Among all the diagnosis, infestations still made of a high frequency, scabies was found at n87( $14.21 \%$ ), as the population of our study consisted of both rural and urban population and from various socioeconomic classes, could be a reason for the higher incidence.

The prevalence of scabies ranged from $0 \cdot 2 \%$ to $71 \cdot 4 \%{ }^{15}$ All regions except for Europe and the Middle East included populations with a prevalence greater than $10 \%$ which corresponds to findings of our study. The uncommon presentations of the pediatric population were also noted in our study, ie. tuberous sclerosis $\mathrm{n} 2(0.33 \%)$, alopecia areata n3 $(0.49 \%)$ which was more common in pediatric females as presented by study, ${ }^{16}$ SLE $n 1(0.16 \%)$, porphyria $\mathrm{n} 1(0.16 \%)$ which was not found commonly among the various similar studies, and have a similar prevalence in international studies. ${ }^{17}$

Though in most of the studies, be it institution based or community based, the infections and infestations were the main group of dermatoses. The higher frequency of allergic reaction in our study could be due to the large urban population attending our hospital.

\section{CONCLUSION}

The present study undertaken shows that there is a higher 
prevalence of infectious dermatological manifestations in the school going age, along with a high prevalence of infestations and allergic manifestations distributed throughout the age groups. Their incidence can be brought down by improving nutrition and personal hygiene of children. Health and wellness of school going children reflects the health status of a community. Our study provides a preliminary baseline data for future epidemiological and clinical research.

\section{REFERENCES}

1. Thappa DM. Common skin problems. The Indian Journal of Pediatrics. 2002;69(8):701-6. DOI: 10.1007/ BF02722708

2. Jain N, Khandpur S. Pediatric dermatoses in India. Indian Journal of Dermatology, Venereology, and Leprology. 2010;76(5):451. DOI: 10.4103/0378-6323.69034

3. WHO. Epidemiology and management of common skin diseases in children in developing countries. 2005. Available from: http://whqlibdoc.who.int/hq/2005/ WHO_FCH_CAH_05.12_eng.pdf [Accessed 20th August 2020].

4. Department of Health Services, Ministry of Health and Population (Nepal). Nepal Department of Health Services Annual Report 2009-10: Available from: http:// ghdx.healthdata.org/record/nepal-department-healthservices-annual-report-2009-2010 [Accessed 20th August 2020].

5. Kumar A, Mishra A, Devkota S, Sathian B, Koirala D P, Paudel U. Pattern of pediatric skin disorders in tertiary care center in Western Nepal. Nepal Journal of Dermatology, Venereology and Leprosy, 2010;9(1):37-9. DOI: 10.3126/kumj.v13i1.13749

6. Sacchidanand S, Sahana M, Asha G, Shilpa K. Pattern of pediatric dermatoses at a referral centre. The Indian Journal of Pediatrics, 2014;81(4):375-80. DOI: 10.1007/ s12098-012-0904-8

7. Poudyal Y, Ranjit A, Pathak S, Chaudhary N. Pattern of pediatric dermatoses in a Tertiary Care Hospital of Western Nepal. Dermatology Research and Practice. 2016. DOI: $10.1155 / 2016 / 6306404$

8. Shrestha R, Shrestha D, Dhakal AK, Shakya A, Shah SC, Shakya H. Spectrum of pediatric dermatoses in tertiary care center in Nepal. Nepal Med Coll J. 2012 ;14(2):146-

\section{PMID: 23671967.}

9. Walker SL, Shah M, Hubbard VG, Pradhan HM, Ghimire M. Skin disease is common in rural Nepal: results of a point prevalence study. British Journal of Dermatology. 2008;158(2):334-8. DOI: $10.1111 / \mathrm{j} .1365-$ 2133.2007.08107.x

10. Basnet B, Neupane S, Shrestha S, Gautam S. Burden of Skin Diseases in Western Nepal: A Hospital Based Study. American Journal of Public Health Research. 2015; 3(5A):64-6. DOI:10.12691/ajphr-3-5A-14

11. Kumar A, Shrestha PR, Pun J, Thapa P, Manandhar M, Sathian B. Burden of Dermatological Disorders in Remote Hilly Region of Western Nepal: A Community Health Camp-based Study. AJPHR. 2015;3(5A):203-5. DOI:10.12691/ajphr-3-5A-43

12. Poudyal AK, Paudel U, Khadka R, Sharma S, Pokhrel K, Das AK, et al. Dermatoses in Himalayas: Pattern of Skin Diseases in Himalayan Region of Nepal. Nepal Journal of Dermatology, Venereology \& Leprology. 2016; 14(1):258. DOI: $10.3126 /$ njdvl.v14i1.15834

13. Horn R. The pattern of skin disease in general practice. Dermatol Pract. 1986; 2:14-9. DOI: 10.4103/00195154.169147

14. Odeibat $\mathrm{H}, \mathrm{Al}$-Tawara M, Omeish I, Al-Smadi RE, Obaidat N. Patterns of skin diseases among pediatric patients attending the pediatric dermatological clinic at King Hussein Medical Center. Journal of the Royal Medical Services. 2014 ;102(1325):1-8. DOI:10.12816/0005526

15. Romani L, Steer AC, Whitfeld MJ, Kaldor JM. Prevalence of scabies and impetigo worldwide: a systematic review. The Lancet infectious diseases. 2015 ;15(8):960-7. DOI: 10.1016/S1473-3099(15)00132-2

16. Nanda A, Al-Fouzan AS, Al-Hasawi F. Alopecia areata in children: a clinical profile. Pediatric dermatology. 2002;19(6):482-5. https://doi.org/10.1046/j.15251470.2002.00215.x

17. Hong $\mathrm{CH}, \mathrm{Tu} \mathrm{HP}$, Lin JR, Lee $\mathrm{CH}$. An estimation of the incidence of tuberous sclerosis complex in a nationwide retrospective cohort study (1997-2010). British Journal of Dermatology. 2016;174(6):1282-9. DOI: 10.1111/ bjd.14415 